\title{
PENENTUAN DENSITAS PLASMA HIDROGEN NONTERMAL PADA TEKANAN RENDAH
}

\author{
Nelda Ipkawati*, Saktioto \\ Program Studi S1 Fisika FMIPA, Universitas Riau \\ *E-mail korespondensi: neldaipkawati89@gmail.com
}

\begin{abstract}
Before producing hydrogen plasma low pressure in experiment, it is necessary to know the density equilibrium process through a simulation. Hydrogen species densities of non-thermal plasma at low pressure is simulated using chemical kinetik model by Runge Kutta method. This simulation carried out to determine the equilibrium process of densities and reaction rates of hydrogen species in achieving equilibrium conditions. The equation used time-dependent continuity equation and Arrhenius form. The hydrogen species consist of electrons, $\mathrm{H}, \mathrm{H}_{2}, \mathrm{H}^{+}$and $\mathrm{H}_{2}{ }^{+}$. The results of show that electron density, $\mathrm{H}, \mathrm{H}, \mathrm{H}_{2}$ and $\mathrm{H}_{2}{ }^{+}$are respectively $10^{20,23} \mathrm{~m}^{-3}, 10^{19,69} \mathrm{~m}^{-3}, 10^{19,91} \mathrm{~m}^{-3}, 10^{19,39} \mathrm{~m}^{-3}$ and $10^{18,43} \mathrm{~m}^{-3}$ during of 23-24 ns. These describe that the density of each species of hydrogen very fast to achieve equilibrium conditions, while the value of the reaction rate obtained can be concluded that the value of the largest reaction rate is the impact ionization process with a value of $9.86 \times 10^{52} \mathrm{~m}$ ${ }^{3} \mathrm{~s}^{-1}$ and the smallest one is dissociation process with a value of $1.22 \times 10^{-5} \mathrm{~m}^{-3} \mathrm{~s}^{-1}$.
\end{abstract}

Keywords: Simulation, Non-thermal Hydrogen Plasma Density, Low Pressure Plasma, Chemical Kinetic Model, MATLAB

\begin{abstract}
ABSTRAK
Sebelum menghasilkan plasma hidrogen secara eksperimen pada tekanan rendah, perlu mengetahui proses kesetimbangan densitas melalui sebuah simulasi. Densitas spesies hidrogen nontermal pada tekanan rendah disimulasikan menggunakan model kinetik kimia dengan metode Runge kutta. Simulasi ini dilakukan untuk mengetahui proses kesetimbangan densitas dan laju reaksi dari spesies hidrogen dalam mencapai kondisi setimbang. Persamaan yang digunakan adalah persamaan kontinuitas yang bergantung pada waktu dan parameter Arrhenius. Spesies hidrogen terdiri dari elektron, $\mathrm{H}, \mathrm{H}_{2}, \mathrm{H}^{+}$dan $\mathrm{H}_{2}^{+}$. Hasil simulasi menampilkan bahwa densitas elektron, $\mathrm{H}, \mathrm{H}_{2}, \mathrm{H}^{+}$dan $\mathrm{H}_{2}{ }^{+}$secara berurutan adalah $10^{20,23} \mathrm{~m}^{-3}, 10^{19,69} \mathrm{~m}^{-3}, 10^{19,91} \mathrm{~m}^{-3}, 10^{19,39} \mathrm{~m}^{-3}$ dan $10^{18,43} \mathrm{~m}^{-3}$ selama23-24 ns. Hal ini menggambarkan bahwa densitas setiap spesies hidrogen sangat cepat dalam mencapai kondisi setimbang, sementara nilai laju reaksi yang diperoleh dapat disimpulkan bahwa nilai laju reaksi yang terbesar adalah proses ionisasi imbas dengan nilai $9.86 \times 10^{52} \mathrm{~m}^{-3} \mathrm{~s}^{-1}$ dan nilai laju reaksi yang terkecil adalah proses disosiasi dengan nilai $1.22 \times 10^{-5} \mathrm{~m}^{-3} \mathrm{~s}^{-1}$.
\end{abstract}

Kata Kunci: Simulasi, Densitas Plasma Hidrogen Nontermal, Plasma Tekanan Rendah, Model Kinetik Kimia, MATLAB.

\section{PENDAHULUAN}

Saat ini penggunaan plasma sudah sangat luas khususnya dalam bidang industri, kesehatan dan teknologi sains. Aplikasi plasma dalam bidang industri sangat menarik perhatian peneliti. Hal ini dikarenakan plasma memiliki kelebihan yaitu mudah dikendalikan, membutuhkan energi yang relatif kecil dalam pengoperasian dan dapat dilakukan dalam skala besar dengan sistem yang sederhana [1]. Dalam bidang indusri seperti industri material, plasma telah diplikasikan sebagai polimerisasi plasma dengan menggunakan metode PE-CVD (Plasma Enhanced-Chemical Vapor Deposition) [2], aktivasi material [3], plasma cutting [4] dan plasma cleaning atau plasma pembersih [5].

Plasma cleaning atau plasma pembersih adalah proses menghilangkan semua bahan organik dari permukaan suatu bahan atau benda menggunakan plasma. Salah satu aplikasi plasma cleaning adalah membersihkan permukaan logam dengan menggunakan plasma hidrogen [5]. Sebelum 
menghasilkan plasma hidrogen yang dapat diaplikasikan dalam plasma cleaning, perlu mengetahui proses kesetimbangan reaksi kinetik kimia dari plasma hidrogen melalui simulasi.

Simulasi plasma hidrogen dilakukan untuk mendapatkan nilai kesetimbangan densitas, waktu dan laju reaksi dalam mencapai kondisi setimbang. Dalam penelitian ini, tekanan yang diinput dalam simulasi adalah tekanan rendah dan jenis plasma yang digunakan adalah plasma nontermal. Spesies plasma hidrogen yang digunakan terdiri dari elektron, $\mathrm{H}, \mathrm{H}_{2}$, $\mathrm{H}^{+}$dan $\mathrm{H}_{2}^{+}$.Untuk mencapai kondisi setimbang, densitas plasma hidrogen akan disimulasikan secara komputasi menggunakan perangkat lunak Matrix Laboratory (MATLAB) dengan metode Runge Kutta.

\section{METODE PENELITIAN}

Metode Runge Kutta digunakan untuk membuat flow chart dan pengkodean program. Sebelum itu perlu untuk menyusun model kinetik kimia dengan menggunakan dua persamaan, yaitu persamaan kontinuitas dan persamaan Arrhenius. Persamaan kontinuitas yang ditinjau hanya bergantung pada waktu saja, sementara persamaan Arrhenius yang digunakan terdiri dari 3 parameter yaitu $\alpha, \beta$ dan $\gamma$ yang nilainya bergantung pada data eksperimen dalam setiap reaksi.

Tabel 1. Daftar nilai input plasma hidrogen nontermal pada tekanan rendah.

\begin{tabular}{llllll}
\hline \multicolumn{1}{c}{ Nilai input } & \multicolumn{5}{c}{ Spesies } \\
\cline { 2 - 5 } & elektron & $\mathrm{H}$ & $\mathrm{H}^{+}$ & $\mathrm{H}_{2}$ & $\mathrm{H}_{2}{ }^{+}$ \\
\hline $\begin{array}{l}\text { Densitas } \\
\text { awal }\left(\mathrm{m}^{-3}\right)\end{array}$ & $1 \times 10^{18}$ & $1,8 \times 10^{20}$ & $9 \times 10^{19}$ & $3 \times 10^{20}$ & $1 \times 10^{19}$ \\
$\begin{array}{l}\text { Temperatur } \\
\text { kinetik (eV) }\end{array}$ & 1 & 0,03 & 0,03 & 0,03 & 0,03 \\
$\begin{array}{l}\text { Tekanan } \\
\text { (N/m }{ }^{2} \text { ) }\end{array}$ & 0,8 & 0,8 & 0,8 & 0,8 & 0,8 \\
$\begin{array}{l}\text { Waktu } \\
\text { Integrasi (s) }\end{array}$ & $1 \times 10^{-9}$ & $1 \times 10^{-9}$ & $1 \times 10^{-9}$ & $1 \times 10^{-9}$ & $1 \times 10^{-9}$ \\
$\begin{array}{l}\text { No.Massa } \\
\text { (amu) }\end{array}$ & 0 & 1,008 & 1,008 & 2,016 & 2,016 \\
\begin{tabular}{l} 
Muatan (e) \\
\hline
\end{tabular} & -1 & 0 & 1 & 0 & 1 \\
\hline
\end{tabular}

Tabel 2. Data reaksi spesies plasma hidrogen nontermal

\begin{tabular}{|c|c|c|c|c|c|}
\hline No & Reaksi & $\alpha\left(\mathrm{m}^{3} \mathrm{~s}^{-1}\right)$ & $\beta$ & $\gamma(\mathrm{K})$ & Referensi \\
\hline 1 & $\begin{array}{l}\mathrm{H}_{2}+\mathrm{H}_{2} \rightarrow \mathrm{H}+\mathrm{H} \\
+\mathrm{H}_{2}\end{array}$ & $2,23 \times 10^{12}$ & 0,5 & 46600 & [6] \\
\hline-1 & $\begin{array}{l}\mathrm{H}+\mathrm{H}+\mathrm{H}_{2} \rightarrow \mathrm{H}_{2} \\
+\mathrm{H}_{2}\end{array}$ & $2,8 \times 10^{-43}$ & $\begin{array}{l}- \\
0,6\end{array}$ & 0 & {$[7]$} \\
\hline 2 & $\mathrm{H}+\mathrm{H}_{2} \rightarrow \mathrm{H}_{2}+\mathrm{H}$ & $6,3 \times 10^{5}$ & 0,5 & 4000 & {$[8]$} \\
\hline-2 & $\mathrm{H}_{2}+\mathrm{H} \rightarrow \mathrm{H}+\mathrm{H}_{2}$ & $6,3 \times 10^{5}$ & 0,5 & 4000 & {$[8]$} \\
\hline 3 & $\begin{array}{l}\mathrm{H}^{+}+\mathrm{H}+\mathrm{e}^{-} \rightarrow \mathrm{H} \\
+\mathrm{H}\end{array}$ & $1,66 \times 10^{-35}$ & $\begin{array}{l}- \\
2,5\end{array}$ & 0 & [9] \\
\hline-3 & & Data reaksi bal & dak t & ssedia & \\
\hline 4 & $\begin{array}{l}\mathrm{H}_{2}+\mathrm{H} \rightarrow \mathrm{H}+\mathrm{H} \\
+\mathrm{H}\end{array}$ & $2,23 \times 10^{12}$ & 0,5 & 46600 & {$[6]$} \\
\hline-4 & $\begin{array}{l}\mathrm{H}+\mathrm{H}+\mathrm{H} \rightarrow \mathrm{H}_{2} \\
+\mathrm{H}\end{array}$ & $8,8 \times 10^{-45}$ & 0 & 0 & {$[10]$} \\
\hline 5 & $\begin{array}{l}\mathrm{e}^{-}+\mathrm{H}_{2} \rightarrow \mathrm{H}_{2}^{+}+ \\
\mathrm{e}^{-}+\mathrm{e}^{-}\end{array}$ & $3,11 \times 10^{-14}$ & 0 & 219324 & {$[11]$} \\
\hline-5 & \multicolumn{5}{|c|}{ Data reaksi balik tidak tersedia } \\
\hline 6 & $\begin{array}{l}\mathrm{H}+\mathrm{e}^{-} \rightarrow \mathrm{H}^{+}+\mathrm{e}^{-} \\
+\mathrm{e}^{-}\end{array}$ & $1,51 \times 10^{31}$ & $\begin{array}{l}- \\
3,0\end{array}$ & 158000 & {$[6]$} \\
\hline-6 & \multicolumn{5}{|c|}{ Data reaksi balik tidak tersedia } \\
\hline 7 & $\begin{array}{l}\mathrm{H}_{2}+\mathrm{e}^{-} \rightarrow \mathrm{H}+\mathrm{H} \\
+\mathrm{e}^{-}\end{array}$ & $2,23 \times 10^{12}$ & 0,5 & 46600 & {$[6]$} \\
\hline-7 & \multicolumn{5}{|c|}{ Data reaksi balik tidak tersedia } \\
\hline 8 & $\begin{array}{l}\mathrm{H}_{2}^{+}+\mathrm{H}+\mathrm{e}^{-} \rightarrow \\
\mathrm{H}+\mathrm{H}_{2}\end{array}$ & $1,66 \times 10^{-35}$ & $\begin{array}{l}- \\
2,5\end{array}$ & 0 & [9] \\
\hline-8 & \multicolumn{5}{|c|}{ Data reaksi balik tidak tersedia } \\
\hline 9 & $\begin{array}{l}\mathrm{H}_{2}^{+}+\mathrm{H}+\mathrm{e}^{-} \rightarrow \\
\mathrm{H}_{2}+\mathrm{H}\end{array}$ & $6,07 \times 10^{-34}$ & $\begin{array}{l}- \\
2,5\end{array}$ & 0 & {$[9]$} \\
\hline-9 & \multicolumn{5}{|c|}{ Data reaksi balik tidak tersedia } \\
\hline 10 & $\begin{array}{l}\mathrm{H}_{2}^{+}+\mathrm{H}_{2}+\mathrm{e}^{-} \rightarrow \\
\mathrm{H}_{2}+\mathrm{H}_{2}\end{array}$ & $6,07 \times 10^{-34}$ & $\begin{array}{l}- \\
2,5\end{array}$ & 0 & {$[9]$} \\
\hline-10 & \multicolumn{5}{|c|}{ Data reaksi balik tidak tersedia } \\
\hline
\end{tabular}

Untuk menjalankan program dalam simulasi ini, diperlukan program yang dibuat dalam bentuk M-file yang terdiri dari program utama dan program data masukan. Program utama terdiri dari program nthequilb.m dan program dlndtn.m. Sementara program data masukan terdiri dari program phycon.m dan program nthdata.m. 
Program nthequilb.m berfungsi untuk mengolah data masukan dan menjalankan semua program lain. Sedangkan program dlndtn.m berfungsi untuk menghitung laju produksi spesies per satuan volume dan mengkoreksi nilai densitas.

Program phycon.m memuat nilai muatan listrik elektron dan konstanta Boltzmann. Sedangkan program nthdata.m memuatnilai parameter Arrhenius, tekanan, nomor massa, muatan dan temperatur kinetik masing-masing spesies plasma hidrogen.

Nilai-nilai parameter Arrhenius $\alpha, \beta$ dan $\gamma$ dari berbagai referensi yang dapat dilihat pada Tabel 2.

\section{HASIL DAN PEMBAHASAN}

\section{Densitas Plasma Hidrogen Nontermal}

Berikut adalah perubahan densitas setiap spesies hidrogen yang dapat dilihat pada Gambar 1.

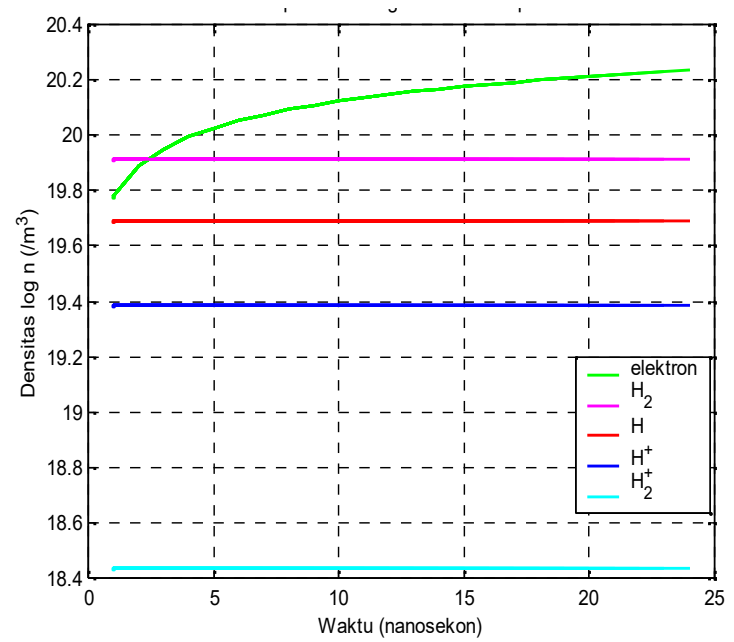

Gambar 1. Perubahan densitas spesies plasma hidrogen nontermal pada tekanan rendah

Gambar 1menunjukkan bahwa spesies plasma hidrogen yang mengalami perubahan nilai densitas yang paling signifikan adalah elektron. Sedangkan spesies $\mathrm{H}, \mathrm{H}_{2}, \mathrm{H}^{+}$dan $\mathrm{H}_{2}{ }^{+}$tidak mengalami perubahan nilai densitas. Hal ini dapat dilihat bahwa grafik yang diperoleh berupa garis lurus, artinya densitas partikel berat dalam plasma hidrogen nontermal tidak berubah densitas karena massa yang dimiliki partikel berat lebih besar dari massa elektron.Nilai densitas spesies plasma hidrogen nontermal pada tekanan rendah dalam kondisi setimbang yang dapat dilihat pada Tabel 3.

Tabel 3.Hasil densitas plasma hidrogen nontermal pada tekanan rendah dalam kondisi setimbang.

\begin{tabular}{cc}
\hline Spesies & Densitas log $\mathrm{n}\left(/ \mathrm{m}^{3}\right)$ \\
\hline Elektron & $10^{20,23}$ \\
$\mathrm{H}$ & $10^{19,69}$ \\
$\mathrm{H}_{2}$ & $10^{19,91}$ \\
$\mathrm{H}^{+}$ & $10^{19,39}$ \\
$\mathrm{H}_{2}^{+}$ & $10^{18,43}$ \\
\hline
\end{tabular}

Nilai densitas spesies plasma hidrogen nontermal yang terbesar adalah densitas elektronsedangkan nilai densitas yang terkecil adalah nilai densitas ion positif hidrogen diatomik $\left(\mathrm{H}_{2}^{+}\right)$.

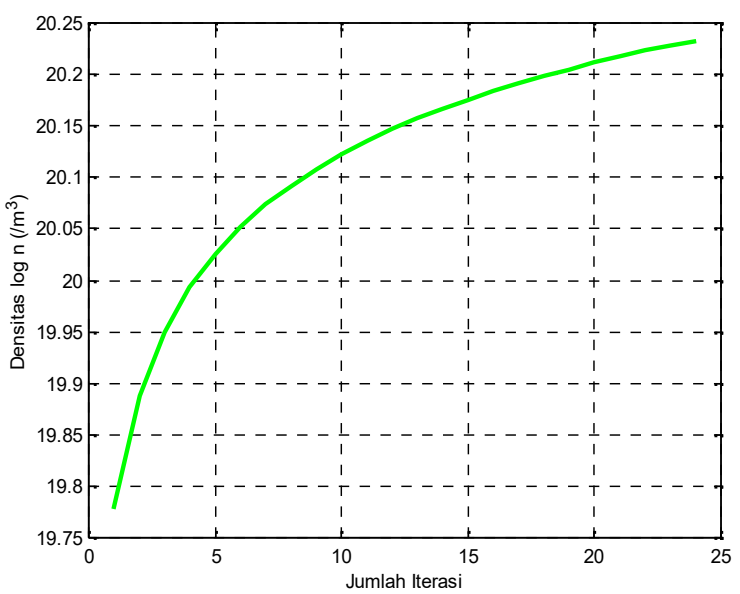

Gambar 2. Perubahan densitas elektron

Dari Gambar 2 dapat dilihat bahwa perubahan nilai densitas elektron menunjukkan kenaikan nilai densitas tiap bertambahnya iterasi sampai nilai densitas elektron mengalami kesetimbangan.

Gambar 3 menunjukkan densitas spesies plasma hidrogen nontermal pada tekanan rendah yang telah mencapai kodisi setimbang dengan rentang waktu 23 - 24 nanosekon, artinya densitas spesies plasma hidrogen nontermal sangat cepat mencapai kondisi setimbang. 


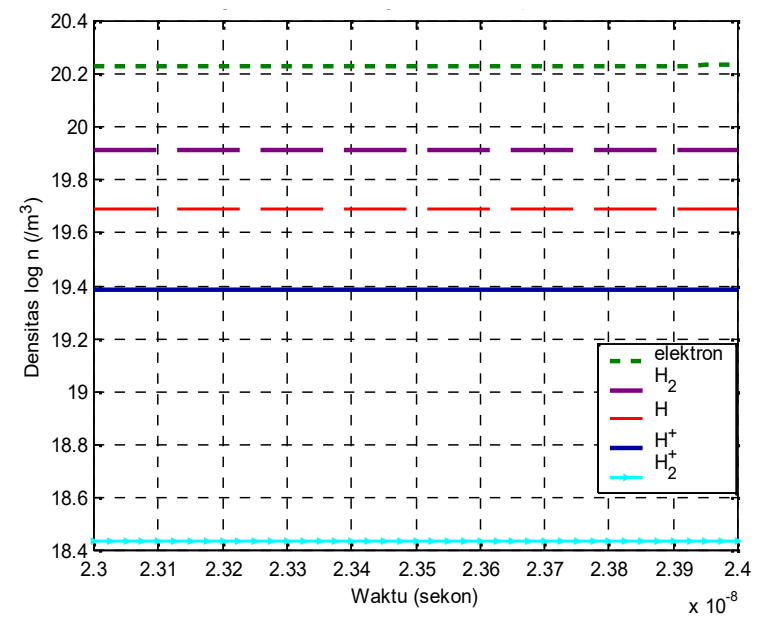

Gambar 3.Kesetimbangan densitas spesies plasma hidrogen nontermal pada tekanan rendah.

\section{Laju Reaksi Plasma Hidrogen Nontermal pada Tekanan Rendah}

Berdasarkan Tabel 4,tiga nilai laju reaksi yang terbesar berturut-turut adalah reaksi nomor 6 yang memiliki nilai laju reaksi sebesar $9.86 \times 10^{52} \mathrm{~m}^{-3} \mathrm{~s}^{-1}$ dengan jenis tumbukan adalah proses ionisasi imbas, reaksi nomor 7 yang memiliki nilai laju reaksi sebesar $6.03 \times 10^{52} \mathrm{~m}^{-3} \mathrm{~s}^{-1}$ dengan jenis tumbukan adalah proses disosiasi dan reaksi nomor 2/-2yang memiliki nilai laju reaksi sebesar $4.78 \times 10^{41} \mathrm{~m}^{-}$ ${ }^{3} \mathrm{~s}^{-1}$ dengan jenis tumbukan adalah proses hamburan elastik. Laju reaksi nomor 2 dan -2 memiliki nilai laju reaksi yang sama besar. Hal ini disebabkan oleh tumbukan yang terjadi antar spesies baik reaksi maju maupun reaksi balik adalah sama sehingga menghasilkan laju reaksi yang sama besar dan tumbukan ini dinamakan dengan hamburan elastik.

Sedangkan tiga nilai laju reaksi yang terkecil berturut-turut adalah nilai laju reaksi nomor 4 yang memiliki nilai sebesar $1.22 \times 10^{-5}$ $\mathrm{m}^{-3} \mathrm{~s}^{-1}$ dengan jenis tumbukan adalah disosiasi, reaksi nomor 1 yang memiliki nilai sebesar $2.03 \times 10^{-5} \mathrm{~m}^{-3} \mathrm{~s}^{-1}$ dengan jenis tumbukan adalah disosiasi dan reaksi nomor 8 yang memiliki nilai sebesar2.60x $10^{13} \mathrm{~m}^{-3} \mathrm{~s}^{-1}$ dengan jenis tumbukan adalah rekombinasi tiga badan.
Tabel 4. Nilai laju reaksi dan jenis reaksi plasma hidrogen nontermal

\begin{tabular}{|c|c|c|c|}
\hline No & Reaksi & $\begin{array}{l}\text { Laju reaksi } \\
\qquad\left(\mathrm{m}^{-3} \mathrm{~s}^{-1}\right)\end{array}$ & $\begin{array}{c}\text { Jenis } \\
\text { tumbukan }\end{array}$ \\
\hline 1 & $\mathrm{H}_{2}+\mathrm{H}_{2} \rightarrow \mathrm{H}+\mathrm{H}+\mathrm{H}_{2}$ & $2.03 \mathrm{e}-005$ & Disosiasi \\
\hline-1 & $\mathrm{H}+\mathrm{H}+\mathrm{H}_{2} \rightarrow \mathrm{H}_{2}+\mathrm{H}_{2}$ & $1.62 \mathrm{e}+015$ & Asosiasi \\
\hline 2 & $\mathrm{H}+\mathrm{H}_{2} \rightarrow \mathrm{H}_{2}+\mathrm{H}$ & $4.78 \mathrm{e}+041$ & $\begin{array}{c}\text { Hamburan } \\
\text { elastik }\end{array}$ \\
\hline-2 & $\mathrm{H}_{2}+\mathrm{H} \rightarrow \mathrm{H}+\mathrm{H}_{2}$ & $4.78 \mathrm{e}+041$ & $\begin{array}{c}\text { Hamburan } \\
\text { elastik }\end{array}$ \\
\hline 3 & $\mathrm{H}^{+}+\mathrm{H}+\mathrm{e}^{-} \rightarrow \mathrm{H}+\mathrm{H}$ & $2.34 \mathrm{e}+014$ & $\begin{array}{c}\text { Rekombinasi } \\
\text { tiga badan }\end{array}$ \\
\hline-3 & \multicolumn{3}{|c|}{ Data reaksi balik tidak tersedia } \\
\hline 4 & $\mathrm{H}_{2}+\mathrm{H} \rightarrow \mathrm{H}+\mathrm{H}+\mathrm{H}$ & $1.22 \mathrm{e}-005$ & Disosiasi \\
\hline-4 & $\mathrm{H}+\mathrm{H}+\mathrm{H} \rightarrow \mathrm{H}_{2}+\mathrm{H}$ & $1.03 e+015$ & Asosiasi \\
\hline 5 & $\mathrm{e}^{-}+\mathrm{H}_{2} \rightarrow \mathrm{H}_{2}^{+}+\mathrm{e}^{-}+\mathrm{e}^{-}$ & $2.68 \mathrm{e}+018$ & Ionisasi imbas \\
\hline-5 & \multicolumn{3}{|c|}{ Data reaksi balik tidak tersedia } \\
\hline 6 & $\mathrm{H}+\mathrm{e}^{-} \rightarrow \mathrm{H}^{+}+\mathrm{e}^{-}+\mathrm{e}^{-}$ & $9.86 \mathrm{e}+052$ & Ionisasi imbas \\
\hline-6 & \multicolumn{3}{|c|}{ Data reaksi balik tidak tersedia } \\
\hline 7 & $\mathrm{H}_{2}+\mathrm{e}^{-} \rightarrow \mathrm{H}+\mathrm{H}+\mathrm{e}^{-}$ & $6.03 e+052$ & Disosiasi \\
\hline-7 & \multicolumn{3}{|c|}{ Data reaksi balik tidak tersedia } \\
\hline 8 & $\mathrm{H}_{2}^{+}+\mathrm{H}+\mathrm{e}^{-} \rightarrow \mathrm{H}+\mathrm{H}_{2}$ & $2.60 \mathrm{e}+013$ & $\begin{array}{c}\text { Rekombinasi } \\
\text { tiga badan }\end{array}$ \\
\hline-8 & \multicolumn{3}{|c|}{ Data reaksi balik tidak tersedia } \\
\hline 9 & $\mathrm{H}_{2}^{+}+\mathrm{H}+\mathrm{e}^{-} \rightarrow \mathrm{H}_{2}+\mathrm{H}$ & $9.49 \mathrm{e}+014$ & $\begin{array}{c}\text { Rekombinasi } \\
\text { tiga badan }\end{array}$ \\
\hline-9 & \multicolumn{3}{|c|}{ Data reaksi balik tidak tersedia } \\
\hline 10 & $\mathrm{H}_{2}^{+}+\mathrm{H}_{2}+\mathrm{e}^{-} \rightarrow \mathrm{H}_{2}+\mathrm{H}_{2}$ & $1.58 \mathrm{e}+015$ & $\begin{array}{c}\text { Rekombinasi } \\
\text { tiga badan }\end{array}$ \\
\hline-10 & \multicolumn{3}{|c|}{ Data reaksi balik tidak tersedia } \\
\hline
\end{tabular}

Analisa Hasil Simulasi

Plasma hidrogen pada tekanan rendah telah disimulasikan oleh beberapa peneliti dengan berbagai parameter, seperti [12] yang telah mensimulasikan densitas hidrogen dengan variasi temperatur pada tekanan rendah dan [13] telah mensimulasikan koefisien laju reaksi hidrogen dengan variasi densitas dan temperatur pada tekanan rendah. Sementara dalam penelitian ini adalah mensimulasikan plasma hidrogen nontermal pada tekanan rendah dengan potensi sebagai plasma cleaning pada logam. 
Dari hasil simulasi yang diperolehdapat diketahui bahwa nilai densitas elektron plasma hidrogen nontermal pada tekanan rendah lebih banyak berionisasi, sehingga menyebabkan nilai densitasnya meningkat dalam mencapai kondisi setimbang sesuai dengan Gambar 2. Selain itu, nilai densitas elektron lebih besar dibandingkan dengan nilai densitas spesies lain disebabkan oleh energi yang diberikan. Semakin besar energi yang diberikan maka semakin besar pula densitas elektron yang dihasilkan. Energi ini berbanding lurus dengan temperatur. Dalam penelitian ini, temperatur elektron yang diinput lebih besar dibandingkan dengan temperatur spesies hidrogen lainnya yaitu sebesar $1 \mathrm{eV}$ sehingga menghasilkan nilai densitas elektron yang besar.

Sedangkan untuk nilai laju reaksi dipengaruhi oleh nilai $\alpha$ yang merupakan salah satu parameter Arrhenius. Nilai $\alpha$ adalah nilai cross section atau tampang melintang dari tumbukan suatu reaksi. Semakin besar cross section maka semakin mudah suatu spesies bertumbukan dengan spesies lain dalam suatu reaksi. Sehingga menyebabkan nilai laju reaksi juga semakin besar. Hal ini terbukti dengan nilai laju reaksi hasil simulasi yang didapatkan bahwa nilai laju reaksi yang terbesar adalah nilai laju reaksi nomor 6 yang memiliki nilai cross section yang cukup besar dibandingkan dengan nilai cross section reaksi yang lain. Selain itu, nilai $\beta$ dan $\gamma$ dari parameter Arrhenius juga sangat mempengaruhi nilai konstanta laju reaksi $(\mathrm{k})$.

\section{KESIMPULAN}

Berdasarkan hasil simulasi yang diperoleh dapat diambil kesimpulanyaitunilai kesetimbangan densitas setiap spesies plasma hidrogen nontermal pada tekanan rendah adalah densitas elektron (ne) $=10^{20,23} \mathrm{~m}^{-3}$, densitas hidrogen monoatomik $(\mathrm{nH})=10^{19,69}$ $\mathrm{m}^{-3}$, densitas hidrogen diatomik $\left(\mathrm{nH}_{2}\right)=10^{19,91}$ $\mathrm{m}^{-3}$, densitas ion positif hidrogen atomik $\left(\mathrm{nH}^{+}\right)$ $=10^{19,39} \mathrm{~m}^{-3}$ dan densitas ion positif hidrogen diatomik $\left(\mathrm{nH}_{2}^{+}\right)=10^{18,43} \mathrm{~m}^{-3}$.
Nilai densitas elektron dari plasma hidrogen pada tekanan rendah lebih banyak berionisasi, sehingga menyebabkan nilai densitasnya meningkat dalam mencapai kondisi setimbang. Interval waktu yang dibutuhkan spesies hidrogendalam mencapai kondisi setimbang adalah 23-24 nanosekon.Nilai laju reaksi yang terbesar merupakan hasil dari proses ionisasi imbasdengan nilai $9.86 \times 10^{52} \mathrm{~m}^{-3} \mathrm{~s}^{-1}$ sedangkan nilai laju reaksi yang terkecil merupakan hasil dari proses disosiasidengan nilai $1.22 \times 10^{-5} \mathrm{~m}^{-3}$ $\mathrm{s}^{-1}$.

\section{DAFTAR PUSTAKA}

1. Ghufron, M., Yunata, E. E., \& Aizawa, T. (2016). Simulasi 1D Pengaruh Tekanan terhadap Densitas Elektron pada Plasma Argon DC Bias Discharge. SMARTICS Journal, 2(1).

2. Bogaerts, A., Neyts, E., Gijbels, R., \& Mullen, J. V. D. (2002). Gas Discharge Plasmas And Their Applications. Spectrochimica Acta, Part B 57, 609-658.

3. Diener. 2007. Plasma Technology. Germany: Diener.

4. Koten, D. S., dkk. (2017). Rancang Bangun Generator Plasma dengan Media Gas Argon. Jurnal EECCIS, 11(1).

5. Astuti, A. R., dkk. (2017). Plasma Pembersih pada Logam. Proceeding of Chemistry Conference, 2.

6. Watanabe, T., Atsuchi, N., \& Shigeta, M. (2006). Two-Temperature Chemically Non-Equilibrium Modeling of Argon Induction Plasmas with Diatomic Gas. International Journal of Heat and Mass Transfer, 49, 4867-4876.

7. Baulch, D. L., Boowman, C. T., Cobos, C. J., Cox, R. A., Just, T., Kerr, J. A., \& Warnatz, J. (2005). Evaluated Kinetic Data for Combustion Modeling: Supplement II. Journal of Physical and Chemical Reference Data, 34(3), 905912. 
8. Westley, F. (1980). Table of Recommended Rate Constants for Chemical Reactions occurring in Combustion. Washington D.C: United States National Standard Reference Data Series-National Bureau of Standards.

9. Tanaka, Y. (2009). Thermally and chemically non-equilibrium modelling of Ar- $\mathrm{N}_{2}-\mathrm{H}_{2}$ inductively coupled plasmas at reduced pressure. Thin Solid Films, 518 (3), 936-942.

10. Cohen, N. \& Westberg, K. (1980). Chemical Kinetic Data Sheets for High Temperature Chemical Reactions. Journal of Physical and Chemical Reference Data, 12(3), 559-562.
11. Kimura, T. \& Kasugai H. (2010). Properties of Inductively Coupled RF $\mathrm{Ar} / \mathrm{H}_{2}$ Plasmas: Experiment And Global Model. Journal of Applied Physics, 107, (8), 083308.

12. Post, D. E. (1995). A Review of Recent Developments in Atomic Processes for Divertors and Edge Plasmas. Shortened PSI Review Paper, 6.

13. Wevers, J. C. A. (1993). A Numerical and Experimental Characterization of $A$ Hydrogen Plasma (Report of a graduation study in the group Equilibrium and Transport in Plasmas). Eindhoven University. 